\title{
IN VITRO EFFECT OF METALLIC SILVER NANOPARTICLES (AgNPs): A NOVEL APPROACH TOWARD THE FEASIBLE PRODUCTION OF BIOMASS AND NATURAL ANTIOXIDANTS IN PEARL MILLET (PENNISETUM GLAUCUM L.)
}

\author{
KHAN, I. ${ }^{1,3 \#}-$ RAZA, M. A. ${ }^{2 \#}-$ AwAN, S. A. ${ }^{3 \#}-$ KHALID, M. H. B. ${ }^{4 \#}-$ RAJA, N. I. ${ }^{3}-$ Min, ${ }^{1} .^{1}-$ \\ ZHANG, A. ${ }^{1}$ - NAEEM, M. ${ }^{2}-$ MeraJ, T. A. ${ }^{2}-$ IQBAL, N. ${ }^{2}-$ ZhANG, X. ${ }^{1}-$ HuANG, L..$^{1 *}$ \\ ${ }^{1}$ Department of Grassland Science, Sichuan Agricultural University, Chengdu, 611130, China \\ ${ }^{2}$ College of Agronomy, Sichuan Agricultural University, Chengdu 611130, China \\ ${ }^{3}$ Department of Botany, PMAS - Arid Agriculture University, Rawalpindi 46000, Pakistan \\ ${ }^{4}$ Maize Research Institute, Sichuan Agricultural University, Chengdu 611130, China \\ *Corresponding author \\ e-mail: huanglinkai@ sicau.edu.cn; phone: +86-187-8357-5058
}

${ }^{\#}$ These authors contributed equally to this work

(Received $18^{\text {th }}$ May 2019; accepted $28^{\text {th }}$ Aug 2019)

\begin{abstract}
Nanotechnology has become a revolutionary science over the past few decades with the potential for positive environmental, health and constructive effects. Nanoparticles (NPs) can be applied almost in every field of science, including the agricultural sector, and attaining great importance in current years. In the present study, Silver nanoparticles (AgNPs) were applied in vitro to examine their effects on economically important crop, pearl millet (P. glaucum L.) grown on MS basal medium supplemented with variable concentrations $(\mathrm{T} 1=$ control, $\mathrm{T} 2=20 \mathrm{ppm}, \mathrm{T} 3=40 \mathrm{ppm}, \mathrm{T} 4=60 \mathrm{ppm}$ and $\mathrm{T} 5=80 \mathrm{ppm}$ ). Effects of AgNPs were assessed by analysing the seed germination, seedlings growth and biochemical profile of pearl millet, which were significantly affected $(p \leq 0.05)$ and observed to be superior under T3 of AgNPs. The highest seed germination, seedling vigour index, root length, shoot length and biomass accumulation were achieved under T3 as compared to other treatments. Antioxidant enzymatic activity, Proline content, Catalase (CAT), Superoxide dismutase (SOD), Peroxidase (POD) including total flavonoids and total phenolic contents were also determined. AgNPs under (T5), inhibited the seed germination and seedlings growth and negatively influenced the biochemical profile by decreasing biomass accumulation. High doses of AgNPs proved to be a stressor and produced more ROS and toxicity, whereas it was indicated that AgNPs at suitable ratio minimized the production of ROS and stabilized the existing mechanisms of plantlets by increasing their growth and biomass production.
\end{abstract}

Keywords: agriculture, constructive, germination, biochemical, accumulation

\section{Introduction}

The world human's population is predicted to reach 9 billion by 2050, from the point of the current 7.4 billion (Hakeem, 2015). Current agricultural practices will not meet the expected demand for food due to the decrease in crop production by various factors, including inefficient means of fertilizers, industrial pollution, insecticides, heavy metals and climatic stresses (Hakeem, 2015). The agriculture sector is a significant contributor of greenhouse gases $\left(\mathrm{CO}_{2}, \mathrm{NO}\right)$ due to overuse of mineral fertilizers, which emitted about $12 \%$ of total greenhouse gases (Hakeem, 2015). A rapid increase in population, depletion of natural resources and climatic issues are the key elements which create pressure on the environment to use chemical fertilizers for projected demand for food 
(Mittal and Mittal, 2013). Demand for environmentally safe agricultural products is growing up with increasing technological advancement. Application of mineral fertilizers and pesticides causes serious intimidations to the environment, resulting in more production of unhealthy food products. For example, the application of nitrogen fertilizers generates the nitrous oxide, which is a greenhouse gas (Vejan et al., 2016). Long term use of mineral fertilizers has resulted in a reduction of soil organic matter leading to acidification of soil and causing severe threats to the survival of plants (Patra et al., 2016). Consequently, excessive use of fertilizers to get more production can result in damaging effects such as pollution, leaching, destruction of friendly insects and micro-organisms which ultimately reduction in soil fertility (Hazra and Das, 2014).

In recent eras, most of the research work has been focused on exploring the effects of nanoparticles (NPs) on plants, including other living organisms (Austin et al., 2016). NPs characterizes significant physiochemical properties and are extensively being used in physics, chemistry, agricultural science, environmental and medicinal field (Majdalawieh et al., 2014; Tripathi et al., 2017) but their interactions with plant metabolism is still needed more attention to exploring on large scale. The application of nanotechnology in agriculture reduces the environmental risks along with high production of agronomical crops (Chaudhuri and Malodia, 2017). In agriculture, metalbased development of NPs such as copper $(\mathrm{Cu})$, iron $(\mathrm{Fe})$, silver $(\mathrm{Ag})$, zinc $(\mathrm{Zn})$ and titanium dioxide (TiO2) has great potential to produce alternative nano fertilizers for crop improvement. Among these, silver nanoparticles (AgNPs) possess more positive effects on the plant's growth and development at suitable concentrations which depend on the size and distribution of AgNPs (Yasur and Rani, 2013).

Several agricultural concerns related to crop production under stress conditions have been elevated and improved by using AgNPs due to their diverse range of chemical and physical properties. Antifungal, antibacterial and antimicrobial properties of AgNPs provide a supreme edge to the farmer for the synthesis and utilization of nano fertilizers that may lessen the cost of agronomic production and enhance sustainable agriculture. Furthermore, AgNPs are cheaper, less toxic and environment-friendly, resulting in more constructive effects on crop yield and production by enhancing seed germination rate, increased seedling growth, i.e. root and shoot length and chlorophyll contents (Rafi and Ramezanian, 2013). Different plant species (e.g. Phaseolus vulgaris, Zea mays and Lycopersicon esculentum) have been exposed to a various dosage of AgNPs, resulted in a significant increase in plant total biomass, lower oxidative stress, increased flavonoid contents and high level of total phenolic contents (Berahmand et al., 2012). AgNPs have been applied with fungicide by seed priming, which enhanced the root length, shoot length and total biomass at lower concentrations while high levels of dosage reduced morphological profile at germination stage in plants. In order to know the beneficial facets of nanotechnology applied to agriculture, penetration, accumulation and transport of NPs should be investigated, which are unexplored yet (Parveen and Rao, 2015). Among the best methods of AgNPs application, foliar spray is demonstrated as most exceptional for agronomic viewpoint as plant leaves may able to intake essential elements more proficiently than roots which are directly in contact with leaf surfaces due to high magnetic properties of AgNPs as compared to other NPs (Chaudhuri and Malodia, 2017; Thakkar et al., 2010).

Pennisetum is the rich genus of Poaceae family. It comprises approximately 140 species that grow under various environmental conditions all over the world (Zhou et al., 2018). P. glaucum is one of the premium and important food crops which occupy 
the sixth rank in the world with the substantial cultivated area $(60 \%)$ in Africa and $(35 \%)$ in Asia. It covers about half of the total global production of millets and is utilized as a staple food, source of protein for human beings and fodder for livestock (Basavaraj et al., 2010; Wang et al., 2018; Zhou et al., 2019b). Seedling stage of plants is susceptible to different types of stresses, which leads to significant loss of crop production in the agriculture system while NPs enhance the germination potential (Parveen and Rao, 2015). Some evidence has shown the excellent effects of phenolic compounds to minimize the risk of non-communicable diseases (NCD) caused by nutritional imbalance and protection against oxidative stress within the human body (Okarter and Liu, 2010).

AgNPs are now widely used in various fields, including agronomic crop production and revealed as stress-reducing agents; however, more research work is still needed to be known that how AgNPs affect antioxidant enzyme essay. The principal objective of recent research work is to explore the influence of AgNPs on seed germination, seedlings growth and biochemical profile in P. glaucum, which is still unexplored. To our best knowledge, this is the first report on the biochemical profiling of in vitro germinated $P$. glaucum seedlings under different concentrations of AgNPs.

\section{Materials and methods}

\section{Plant material and sterilization}

Seeds of Pennisetum glaucum (L.) R. Br. were obtained from the key laboratory of Grassland Science, Sichuan Agricultural University, China and used as an explant for this experiment. Seeds were well washed with simple tap water and dipped in ethanol for $30 \mathrm{~min}$. Then sterilized in $0.1 \%$ mercuric chloride $\left(\mathrm{HgCl}_{2}\right)$ for 4 minutes and rinsed with autoclaved distilled water.

\section{Seed germination experiment}

The experiment was carried out in the key laboratory of Grassland Science, Sichuan Agricultural University, China. In this experiment, synthesized silver nanoparticles (AgNPs) were obtained from NANOCS (Nanocs lnc. New York, NY 10001, USA), manufactured according to $>0.75 \mathrm{~A} 520$ units $/ \mathrm{m}$ having $100 \mathrm{~nm}$ sizes (solution form). Firstly, the dilution of nanoparticles was taken out by using a stock solution. Five different types of treatments of AgNPs $(\mathrm{T} 1=$ control, $\mathrm{T} 2=20 \mathrm{ppm}, \mathrm{T} 3=40 \mathrm{ppm}$, $\mathrm{T} 4=60 \mathrm{ppm}$ and $\mathrm{T} 5=80 \mathrm{ppm}$ ) were applied to MS medium. Sterilized seeds were inoculated in the conical flasks having MS solid medium and allowed them to germinate under controlled laboratory conditions at the temperature of $30 \pm 5{ }^{\circ} \mathrm{C}$ (Hussain et al., 2017). Seed germination was experiential in 4-5 days and data were collected after ten days of germination. The experiment was repeated in twice, and data were taken out in triplicate.

\section{Germination parameters}

\section{Germination frequency percentage}

Seeds were considered as germinated when radical has taken out from the seed coat (Hussain et al., 2017). 
Germination frequency $=$ No. of seeds germinated $\times 100 /$ total no. of seeds

Shoot and root morphology

Length of shoot and root was measured in $\mathrm{cm}$ and compared by using a bar chart.

Seedling vigour index (SVI)

This was calculated by using the method of Ushahra and Malik (2013) and expressed as:

$$
\text { SVI }=[\text { root length }+ \text { shoot length }] \times \text { germination percentage }
$$

\section{Biochemical profiling}

\section{DPPH activity}

For the estimation of antioxidant activity, a protocol described by Abbasi et al. (2010) was used for DPPH (2, 2-diphenyl-1-picrylhydrazyl) free radical scavenging assay (FRSA). $10 \mathrm{mg}$ of dried plant samples were dissolved in $4 \mathrm{ml}$ methanol and then mixed with $0.5 \mathrm{ml}$ of DPPH solution. The mixture was gently vortexed for fifteen seconds and placed at room temperature for $30 \mathrm{~min}$. Final results were concluded when the sample absorbance was checked by spectrophotometer at $517 \mathrm{~nm}$. FRSA was calculated and expressed as:

\section{DPPH discoloration \%age $=100 \times\left(1-\mathrm{A}_{\mathrm{s}} / \mathrm{A}_{\mathrm{b}}\right)$}

$A_{s}$ : Absorbance of the solution with extract addition. $A_{b}$ : Absorbance of the solution without extract addition.

\section{Proline contents}

Proline contents were measured according to Bates et al. (1973), $0.5 \mathrm{~g}$ of plant samples were homogenized by pestle and mortar in $5 \mathrm{ml}$ of $3 \%$ sulphosalycylic acid. $2 \mathrm{ml}$ of ninhydrin reagent and $2 \mathrm{ml}$ of glacial acetic acid were added to the test tube having $2 \mathrm{ml}$ of extract. The mixture was placed in a water bath and boiled at $100{ }^{\circ} \mathrm{C}$ for $30 \mathrm{~min} .6 \mathrm{ml}$ of toluene was added to a reaction mixture after cooling and transferred to separating funnel. Thoroughly mixing resulted separation of the chromophore with toluene and absorbance was measured at $520 \mathrm{~nm}$ by using a spectrophotometer DU-730 (Beck Man Coulter Inc., USA)

Antioxidant enzyme extracts were prepared by using mortar and pestle. Plant samples $(1 \mathrm{~g})$ were homogenized with $10 \mathrm{ml}$ of extraction buffer containing $(50 \mathrm{mM}$ potassium (K)-phosphate buffer with $1 \%$ polyvinyl polypyrrolidone at $\mathrm{pH} 7$ ). The mixture was centrifuged at $15,0000 \mathrm{~g}$ for $30 \mathrm{~min}$ at $4{ }^{\circ} \mathrm{C}$ and supernatant was used for Antioxidant enzyme activity (Ullah et al., 2015).

\section{Superoxide dismutase (SOD)}

One of the methods described by Ullah et al. (2015) with some improvements was used to measure the SOD activity. $1 \mathrm{ml}$ of the reaction mixture was composed of 1 millimolar (mM) EDTA, 130 millimolar methionine, 0.05 molar phosphate buffer ( $\mathrm{pH}$ 7) 0.02 millimolar riboflavin and 0.75 millimolar nitroblue tetrazoliums (NBT). The 
reaction mixture was placed under the fluorescent light for $7 \mathrm{~min}$ and absorbance was measured at $560 \mathrm{~nm}$ using spectrophotometer DU-730 (Beck Man Coulter Inc., USA). By using the Lambert-Beer law equation, SOD activity was calculated:

$$
\mathrm{A}=\varepsilon \mathrm{LC}
$$

A: absorbance, $\varepsilon$ : extinction coefficient, L: length of each wall, C: concentration of enzymes.

\section{Catalases and peroxidases activity}

The protocol of Aebi (1984) was used with some modifications to determine the catalase activity. Enzyme extract $(0.5 \mathrm{ml})$ was added to $3 \mathrm{ml}$ of reaction solution (50 mM phosphate buffer, $\mathrm{pH} 7.0$ and $30 \% \mathrm{w} / \mathrm{v} \mathrm{H}_{2} \mathrm{O}_{2}$ ). The catalase activity was examined at the decrease of absorbance at $240 \mathrm{~nm}$ using spectrophotometer DU-730 (Beck Man Coulter Inc., USA). The estimation of peroxidase activity was measured by following the method of Chance and Maehly (1955). $3 \mathrm{ml}$ of reaction solution containing ( $20 \mathrm{mM}$ guaiacol, ten $\mathrm{mM}$ phosphate buffer and ten $\mathrm{mM} \mathrm{H} \mathrm{H}_{2} \mathrm{O}_{2}$ ) was mixed with $0.5 \mathrm{ml}$ of enzyme extract (heated in a water bath at $45{ }^{\circ} \mathrm{C}$ for 5 min before mixing). Increase in absorbance was measured at $470 \mathrm{~nm}$ using spectrophotometer DU-730 (Beck Man Coulter Inc., USA) due to the formation of tetraguaiacol (Klapheck et al., 1990).

\section{Estimation of total phenolic content (TPC)}

For TPC estimation, $0.75 \mathrm{ml}$ of Folin-Ciocalteu reagent was added to $100 \mu \mathrm{l}$ plant extract, gently mixed and placed them at $22{ }^{\circ} \mathrm{C}$ for $5 \mathrm{~min} .0 .75 \mathrm{ml}$ of $\mathrm{Na}_{2} \mathrm{CO}_{3}$ solution was then added to the mixture and kept at $22{ }^{\circ} \mathrm{C}$ for $90 \mathrm{~min}$. Final results were concluded by checking sample absorbance at $725 \mathrm{~nm}$ at UV/Vis-DAD spectrophotometer (UV-2250, Kyoto, Japan) (Velioglu et al., 1998).

\section{Estimation of total flavonoids content (TFC)}

For the estimation of TFC, $\mathrm{AICI}_{3}-\mathrm{NaNO}_{2}-\mathrm{NaOH}$ reaction complex was used according to the protocol given by Lopez-Contreras et al. (2015). $0.2 \mathrm{ml}$ of extract was added to $3.5 \mathrm{ml}$ of distilled water. Furthermore, $(0.15 \mathrm{ml}) 5 \% \mathrm{NaNO}_{2},(0.15 \mathrm{ml})$ $10 \% \mathrm{AlCl}_{3}$ and $(1 \mathrm{ml}) 1 \mathrm{M} \mathrm{NaOH}$ were added to mixture by equal $5 \mathrm{~min}$ time intervals each and placed it at room temperature for 15 mins. Reaction absorbance was measured at $510 \mathrm{~nm}$ by using UV/Vis-DAD spectrophotometer (UV-2250, Kyoto, Japan).

\section{Statistical analysis}

All the data were analysed by using Statistical software (version 7.0; StatSoft). Significance was determined via one-way analysis of variance. Values are presented as mean \pm standard error (SD) from three independent biological replicates. A comparison of the means (control + treatments) was confirmed by Duncan's multiple range test at $p<0.05$. 


\section{Results}

\section{Silver nanoparticles and germination percentage}

In the recent study we have explored the in vitro phytotoxic and beneficial aspects of synthesized metallic silver nanoparticles (AgNPs) in Pennisetum glaucum (L.), AgNPs were purchased from China which possessed the size of $100 \mathrm{~nm}$ (Fig. 1A). AgNPs did not show any adverse effect on seed living mechanism. Interestingly, AgNPs have boosted the seed germination in P. glaucum (L.) as compared to non-treated. The enhancement in seed germination has been assessed as dispersed AgNPs could create 'nanoholes' in the seed coats and make their entry easier to seeds via seed coat, resulting in enhanced germination conditions, slow and slight release of silver ion $\left(\mathrm{Ag}^{+}\right)$ could be a second primary reason for Ag-nanoparticles to have no deleterious effects on germination of $P$. glaucum (L.) seeds at optimal concentrations.

Moreover, the maximum seeds germination percentage (99\%) was recorded in T3 of AgNPs (Fig. 1B). This was observed as the appropriately applied ratio of AgNPs, which resulted in enhanced germination of seeds in vitro and possible to utilize in the agricultural system for better crop production. This may elucidate, at the optimal range of applied AgNPs, seeds germination was not altered harmfully so AgNPs could be used as conventional fungicides to protect the seeds against fungi and reduce environmental sways of fungicides as well as lower the cost of agricultural production.

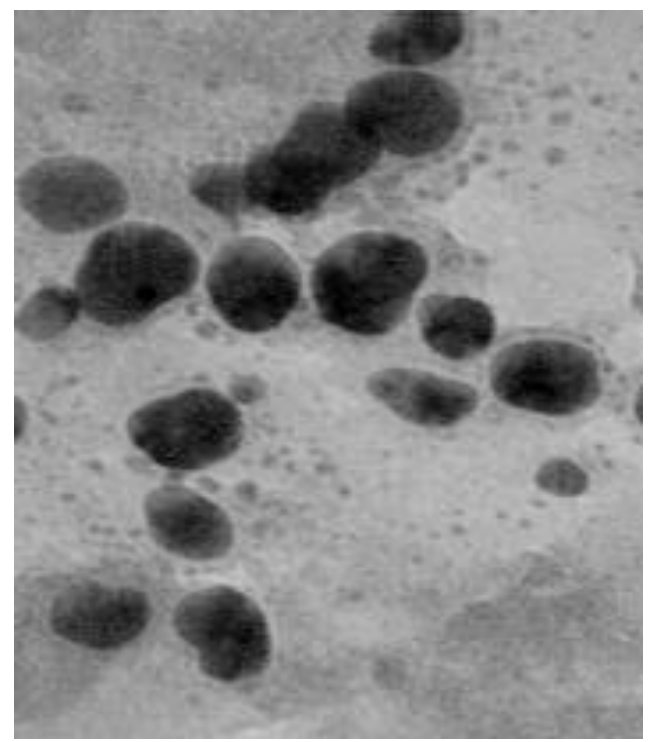

(A)

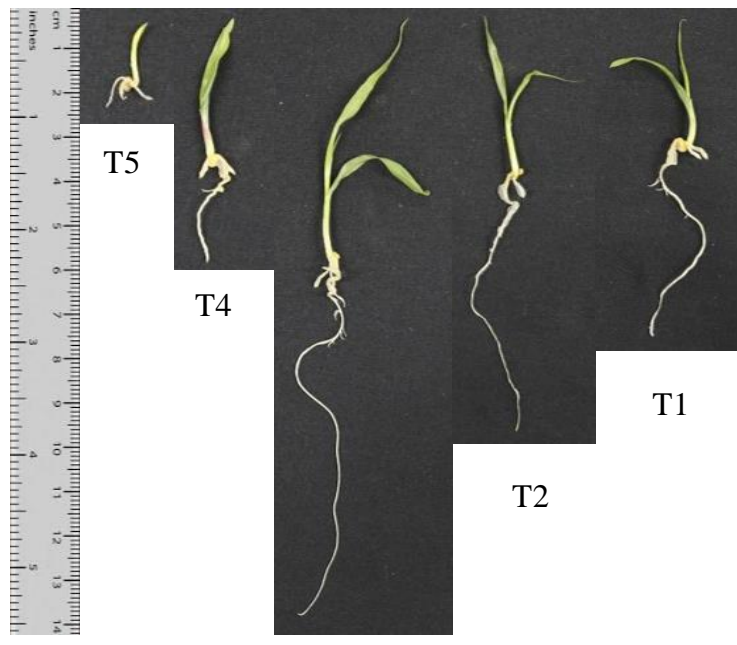

T3

(B)

Figure 1. (A) Transmission electron microscopy (TEM) images of metallic silver nanoparticles having size of $100 \mathrm{~nm}$. (B) Effect of different treatments $(T 1=0 \mathrm{ppm}, T 2=20 \mathrm{ppm}, T 3=40$ ppm, T4 $=60 \mathrm{ppm}$ and T5 $=80 \mathrm{ppm}$ ) of metallic silver nanoparticles (AgNPs) on growth of

Pennisetum galucum (L.) seedlings. Each seedling represented an experimental unit

The Figure $2 A$ and $B$ indicate that seed germination percentage and seed vigour index affected by various treatments of AgNPs. Germination percentage at control (T1) and T3 was $92 \%$ and $99 \%$ respectively while in comparison with T5, it was strongly reduced to $66 \%$. These results revealed that AgNPs application at T3 sharply boosted the germination potential by increasing emergence speed of radical and plumule in $P$. 
glaucum (L.) seeds on MS solid media. Though the emergence response of seeds was dependent on applied concentration in $\mathrm{T} 5$, a noticeable reduction in germination was observed.

(A)

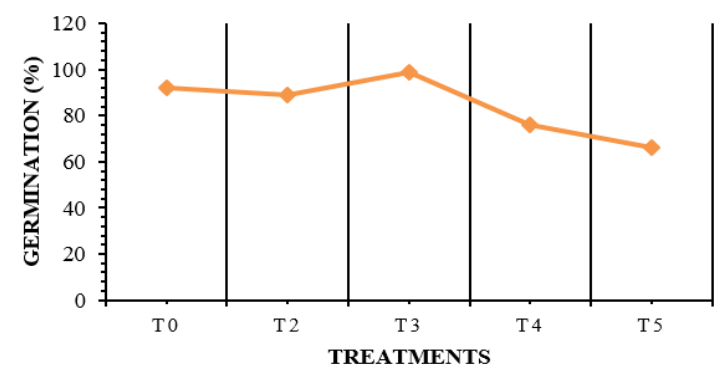

(C) Shoot length

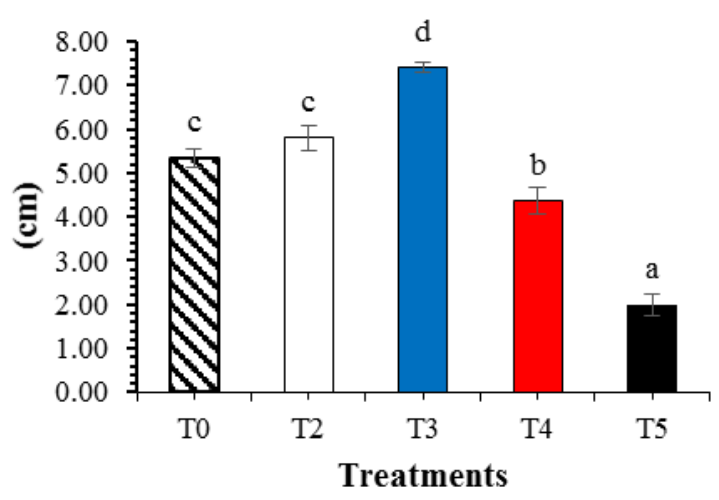

(E) Fresh Biomass

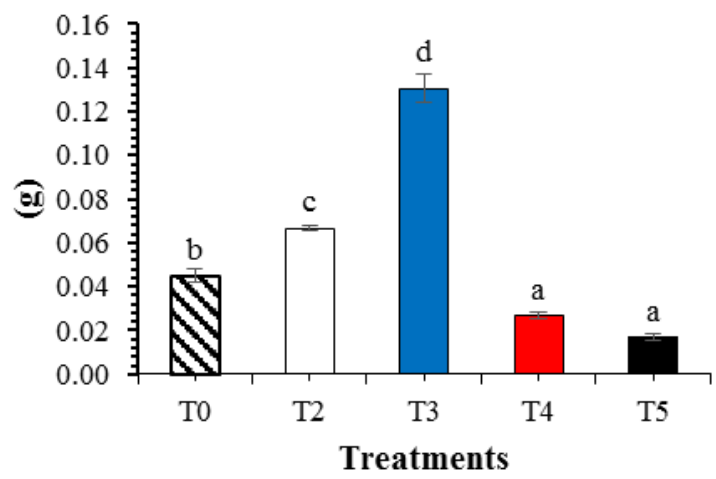

(B)

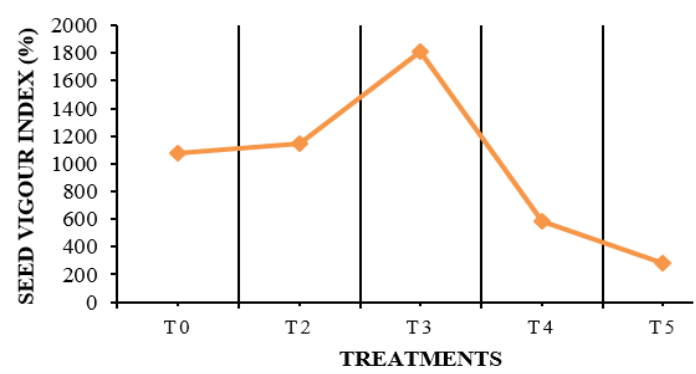

(D) Root length

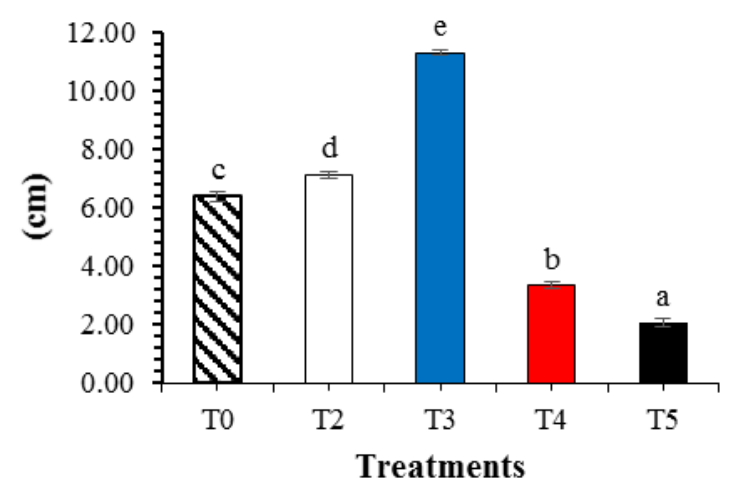

(F) Dry Biomass

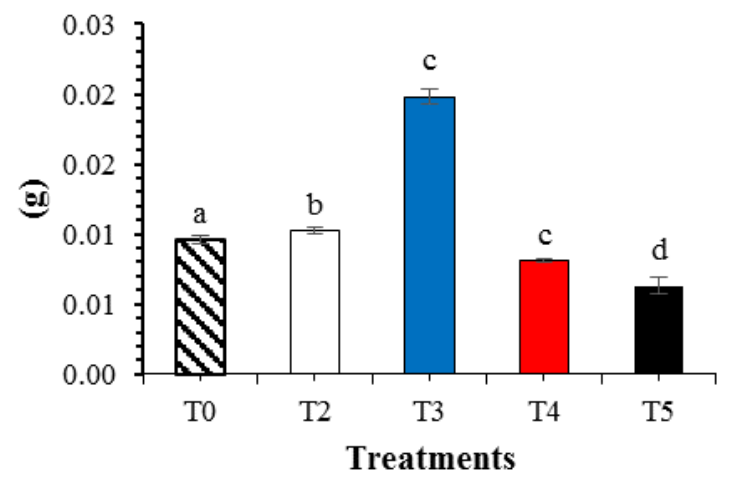

Figure 2. The response of seed germination and seedling growth treated with AgNPs (A) Seed germination potential, (B) Seed vigour index, (C) Shoot length (D) Root length (E) Fresh biomass $(F)$ Dry biomass. Values are the average of three repetitions. Means $(n=3)$ and standard errors ( \pm ) were calculated by analysis of variance (one-way). A comparison of the means (control + treatments) was confirmed by Duncan's multiple range test at $p<0.05$

\section{Morphological parameters and total biomass}

Under T5, root length, shoot length and seedling vigour index (SVI) were significantly reduced, as shown in Figure 2. In case of seedlings growth, the length was 
enhanced up to $76.5 \%$ and $38.8 \%$ in root and shoot respectively in T3 which showed best results as compared to control while rapidly reduced as concentrations of nanoparticles increased or decreased. It was noticed that higher concentrations of AgNPs had a deleterious effect on plantlets, resulting in a significant reduction in root and shoot length and SVI. Consequently, the fresh and dry biomass were dependent on better seedling growth. In comparison with control, fresh and dry biomass were enhanced (190.1\%) and (106.2\%) respectively in T3 and readily decreased to $163.2 \%$ and 52.38\% at high doses (T5) (Fig. 2E, F). The highest reduction in biomass could be due to more accumulation of ions released from nanoparticles, which reduced the availability of nutrients to seedlings for growth at higher doses (Hussain et al., 2017).

\section{Antioxidant activity}

\section{DPPH radical scavenging assay}

DPPH (2, 2-diphenyl-1-picrylhydrazyl) free radical scavenging activity of plantlets treated with AgNPs is presented in Figure 3. AgNPs suspension significantly influenced the DPPH activity in P. glaucum (L.). The highest DPPH activity $(26 \%)$ was recorded in the plantlets which were exposed to T5 while others showed less. In contrast with others, T3 had reduced the antioxidant activity (9\%) even then control (13\%), revealed less production of ROS at this concentration which was advantageous for plant metabolisms and successful growth (Zhou et al., 2019a) as found in Figure 3.

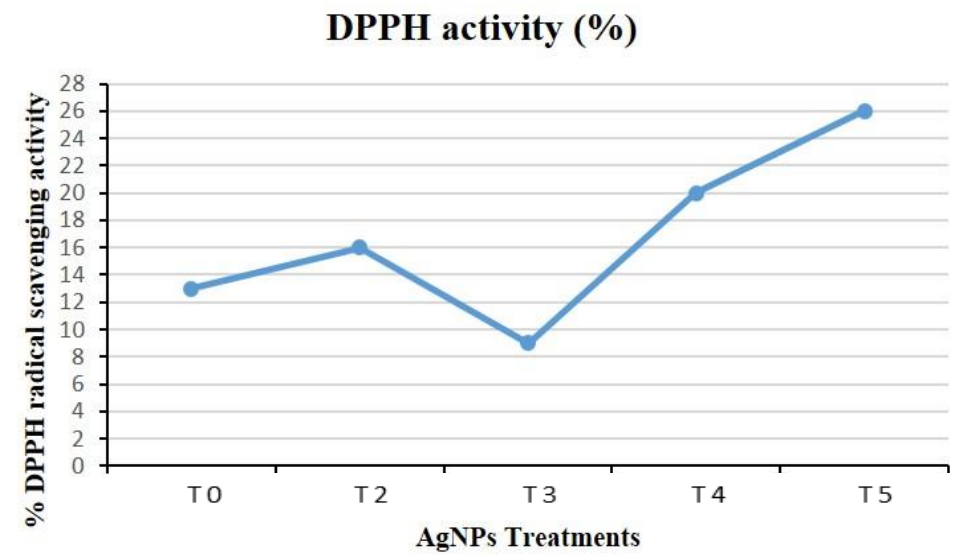

Figure 3. Percentage DPPH radical scavenging activity of P glaucum L. against different treatments of metallic silver nanoparticles (AgNPs)

\section{Proline and superoxide dismutase (SOD) activity}

Proline contents and SOD activity also have been evaluated in the present investigation, as shown in Figure $4 A, B$. Proline contents were relatively less $(1.12 \pm 0.0152 \mu \mathrm{g} / \mathrm{mg})$ in the seedlings treated with $\mathrm{T} 3$ as compared all other treatments, including control $(1.17 \pm 0.0264 \mu \mathrm{g} / \mathrm{mg})$. However, the highest value $(2.15 \pm 0.435 \mu \mathrm{g} / \mathrm{mg})$ was found at $\mathrm{T} 5$, which reflected the stressed conditions faced by plantlets. By increasing the AgNPs doses, SOD activity tends to become more and highest at T5 $(0.048 \pm 0.0043 \mu \mathrm{mol} / \mathrm{mg})$ and lower at T3 $(0.031 \pm 0.0020 \mu \mathrm{mol} / \mathrm{mg})$. Stress could be a critical factor which enhanced the Proline and SOD activity (Mohamed et al., 2017). 


\section{(A) Proline}

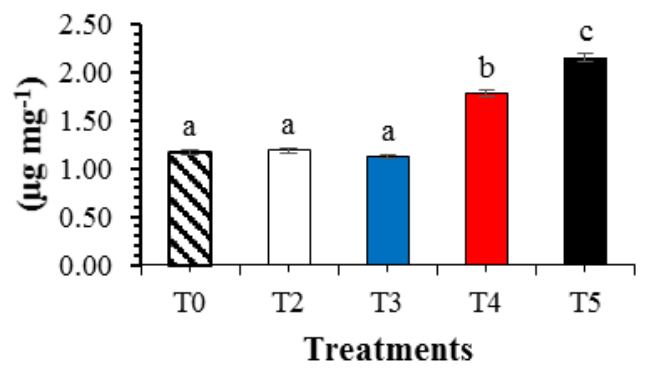

(B) Superoxide Dismutase

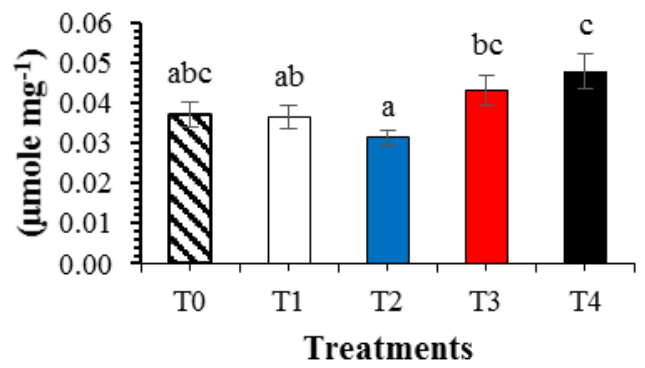

Figure 4. Antioxidant enzyme activity in P glaucum L. seedlings treated with AgNPs. (A) Proline content. (B) Superoxide dismutase (SOD) activity. Values are the average of three repetitions. Means $(n=3)$, and standard errors $( \pm)$ were calculated by analysis of variance (one-way). A comparison of the means (control + treatments) was confirmed by Duncan's multiple range test at $p<0.05$

\section{Catalases (CAT) and peroxidases (POD) activity}

Our results showed a negative relationship between CAT and POD activity as seen in Figure 5A, B, at higher dose (T5) more POD activity $(1.03 \pm 0.723 \mu \mathrm{g} / \mathrm{g})$ was recorded, however POD activity was significantly decreased to $101.9 \%$ and $68.8 \%$ in T3 and T1 respectively, which strongly reflected the consistent and sustainable living mechanism of plantlets whereas, more POD activity resulted in more stress on plantlets. The CAT activity was seemed to be higher $(141 \pm 2.081 \mathrm{mg} / \mathrm{g})$ in $\mathrm{T} 3$ and lower as the dosage increased from T3. However, lowest CAT activity $(100 \pm 3.833 \mathrm{mg} / \mathrm{g})$ was recorded in the plantlets treated with $\mathrm{T} 5$, at this concentration plantlets were observed in stress condition which could be due to more production of ROS. Furthermore, CAT is found in peroxisome (Alberts et al., 2002) so, AgNPs at the suitable ratio may cause more production of catalases that provide longevity to plantlets under different environmental settings.

\section{Total phenolic contents (TPC) and total flavonoids contents (TFC)}

Total phenolic contents in the seedlings which treated in T3 were comparatively more $(0.56 \pm 0.0152 \mu \mathrm{g} / \mathrm{mg})$ than control and T2, as shown in Figure $5 D$. On the contradictory, there were significant effects $(p \leq 0.01)$ in the phenolic compound's accumulation since the rise in doses from T3 to T5, declined in the accumulation of total phenolic contents $(12.1 \%)$ and $(35.2 \%)$ under T4 and T5 respectively when compared with $\mathrm{T} 1$. These results indicated that seedlings exposed to higher doses of 
AgNPs faced more stress by which they accumulated less phenolic compounds because a high dosage of AgNPs acted as a stressor and inhibited the accrual of TPC.

Unlike phenolic compounds, the flavonoid contents were higher as the concentrations of AgNPs increased from $\mathrm{T} 2$ to $\mathrm{T} 5$ as in Figure 5C. Total flavonoid contents were significantly enhanced to $0.58 \pm 0.0233 \mu \mathrm{g} / \mathrm{mg}$ under T3 than $\mathrm{T} 1$, resulting from the proper entry of nanoparticles into seeds at the time of germination which provided signals to emerging seedlings by which these could cope with different environmental settings. Therefore, significant differences have been recorded at high doses of AgNPs when compared with T3. A higher concentration of nanoparticles produced more TFC $(0.76 \pm 0.055 \mu \mathrm{g} / \mathrm{mg})$, but a significant reduction in seedling growth was observed.

(A) Catalase

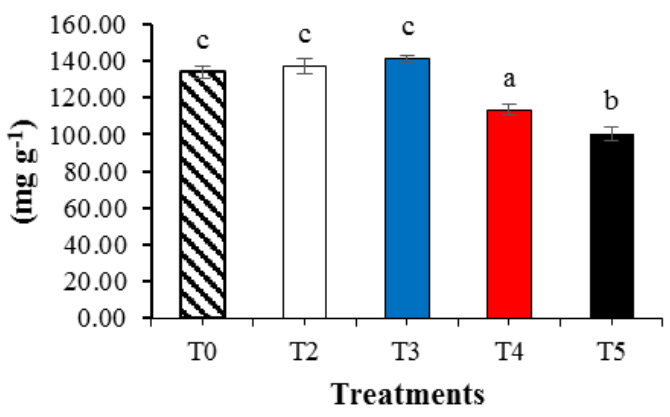

(C) Total Flavonid Content

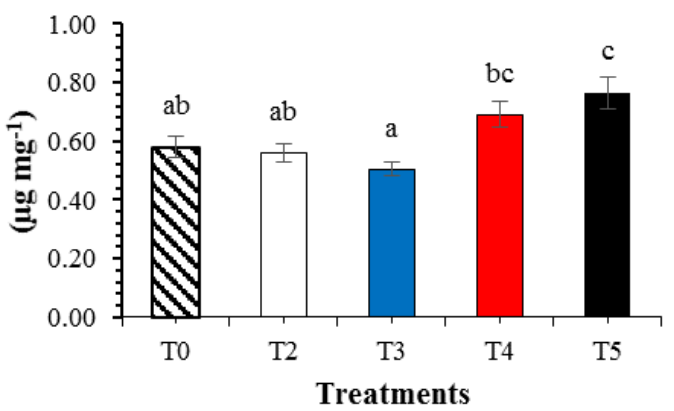

(B) Peroxidase

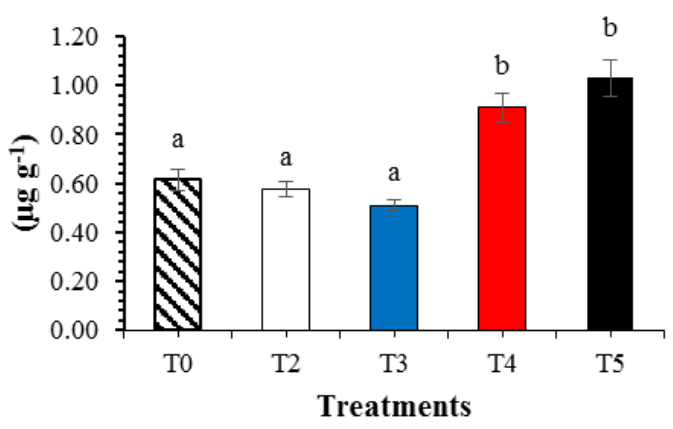

(D) Total Phenolic Content

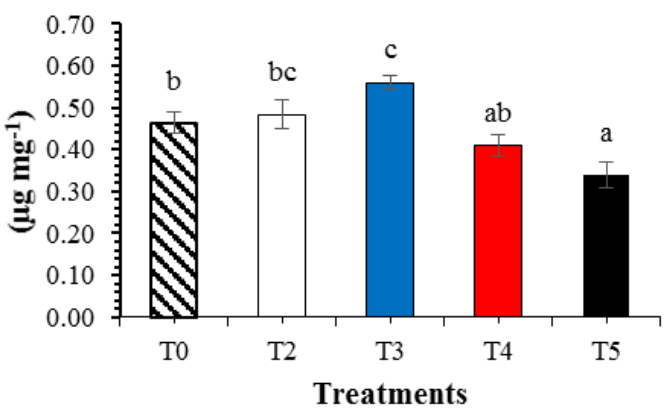

Figure 5. Antioxidant enzyme activity and phenolic content in Pennisetum galucum L. seedlings treated with AgNPs. (A) Catalase (CAT) activity, (B) Peroxidase (POD) activity, (C) Total flavonoid content $(T F C)(D)$ Total phenolic content $(T P C)$. Values are the average of three repetitions. Means $(n=3)$ and standard errors $( \pm)$ were calculated by analysis of variance (one-way). A comparison of the means (control + treatments) was confirmed by Duncan's multiple range test at $p<0.05$

\section{Discussion}

Results of recent research work disclosed that suitable concentrations of AgNPs significantly enhanced the seed germination, growth attributes and improved the biochemical profile of P. glaucum (L.) while high dosage acted as a stressor or toxic to plants at germination stage and reduced the total biomass. Study of the toxicity of nanomaterial is the nanotoxicology, which is dependent on their sizes, shapes and effects because nanoparticles have distinctive properties. Although toxicity mechanism 
of nanoparticles is still unknown nonetheless, it would depend upon the nanomaterials chemical composition, chemical structure, sizes and surface area. Two major key factors can be the cause of toxicity (1) release of more toxic ions and (2) stress due to size, shape or surface of nanomaterial. NPs bearing small sizes have more surface area, so these are more toxic (Parveen and Rao, 2015). In case of metallic nanoparticles (MNP), small-sized CuNPs have been observed more toxic on two plant species wheat (Triticum aestivum) and mung bean (Phaseolus radiatus) by reducing seedling growth than other MNPs (Lee et al., 2008). However, High emergence percentage of root and shoot from seeds is triggered by the positive role of plant hormones. Nanoparticles were entered to seeds successfully and filled the space between permeable membrane which enhanced the biosynthesis of hormones especially auxins and gibberellins to degrade seed reserves resulted from increased seed germination and seedling growth (El-Kereti et al., 2013; van Dongen et al., 2003).

It was observed in our findings that maximum germination percentage and seedling growth were attained at T3, this range could be a suitable for rapid entry of AgNPs and positive acceleration of seed metabolism for the enhancement of seedling growth as shown in Figure 1B. Kumari et al. (2011) reported that AgNPs influenced the cell division process of plant and caused cell enlargement, where they interfered with plant components in plant systems and translocated from stem to leaves. Interestingly, lower concentrations of AgNPs were seemed to be useful to increase the seed vigour and seedlings growth and had no deleterious effects to cell division process and seedlings growth in kinnow (Hussain et al., 2018). High dosage of AgNPs inhibited or reduced the seed germination, decreased seedlings growth, chlorophyll contents, and plant biomass in Hordeum vulgare and Spirodela polyrhiza which strongly affirm our recent findings in case of P. glaucum (L.). Besides, AgNPs possess antiviral, antifungal, antibacterial properties and can be utilized as potent fungicides due to their strengthening shielding role against fungi and enhanced germination frequency as described by Karimi et al. (2012), who reported the better germination potential and seedling growth from the seeds, coated with a suitable concentration of AgNPs solution compared with fungicides coated seeds. Same results for growth parameters were investigated by Hussain et al. (2017), who achieved 98.6\% germination vigour which was about $7 \%$ better than control and $22 \%$ more seedling growth compared with control in Artemisia under suitable concentrations (30 mg/L) of AgNPs. Study of AgNPs on rice (Oryza sativa) seedlings also have been examined, and results revealed, as a dosage of NPs increased from $60 \mathrm{mg} / \mathrm{L}$ all the growth attributes including seed germination, root length, shoot length, leaf length, leaf area and biomass readily decreased (Mirzajani et al., 2013). Total biomass reduction in wheat (Triticum aestivum) and (Pennisetum glaucum) under high concentrations of AgNPs was also reported by Mohamed et al. (2017) and Khan et al. (2019). Reduction in total biomass (fresh and dry) accumulation due to the high amount of AgNPs has been shown in Figure 2. We have applied AgNPs to $P$. glaucum on MS basal medium while most of the above described findings were achieved in soil experiments in which other plant species have been experienced, but all these strongly affirm our best germination results under suitable concentrations and poor results under the high ratio of NPs as in Figure $1 B$.

In the present study, ranges of AgNPs above T3 negatively affected the root and shoot growth, alternatively increased the antioxidant activity, total flavonoids and proline contents. Likewise, under stressed conditions, Triticum aestivum increased MDA contents and $\mathrm{H}_{2} \mathrm{O}_{2}$ level resulting in increased antioxidant activity to cope with 
the stress for better survival of plant (Mohamed et al., 2017). A higher concentration of AgNPs led to more production of ROS and such behaviour caused the blockage of electron transfer that induced the oxidative stress (Zou et al., 2016). It was in support of our findings, as shown in Figure 3 that more the DPPH activity at the maximum NPs concentration. A similar report was described by García-López et al. (2018), in the case of ZnNPs, increased DPPH activity was recorded at high concentrations in Capsicum аппииат. Proline, as a multifunctional amino acid triggered the plant growth through signalling mechanism, upregulated and accumulated in a large amount under stressed conditions and optimal under normal growth settings (Yang et al., 2009). Our results demonstrated that a high level of proline was observed in T5 while lower at T3 than T1 that is associated with the above findings and presented in Figure 4. Our results indicated healthy and progressive plants growth under an ideal range of NPs (T3) by minimizing proline contents less than control because plants enhance the endogenous proline level when suffered from more stress (Szabados and Savoure, 2010).

Furthermore, we have observed that changes in morphology and accumulation of secondary metabolites with greater efficacy under high ranges of AgNPs resulted in oxidative stress in P. glaucum (L.). More ROS lead to more antioxidant production, which was previously reported by Sewelam et al. (2016) as ZnNPs applied to plants in higher concentrations. Our results exhibited increased SOD and POD activities at higher AgNPs ranges than T1. This reflects the development of a well-defined antioxidant defensive mechanism to cope with stress (Gill and Tuteja, 2010). However, the optimum range of NPs (T3) showed less SOD and POD activity and in plantlets instead of control which indicated a small amount of ROS production by decreasing cell damage risk due to NPs and enhanced the plant growth. According to present research work, this optimal concentration of NPs could be used under stress condition for the inhibition of ROS production. Our findings are associated with Parry et al. (1994), who reported more production of antioxidants under stress condition which mitigated the biosynthesis of the enzymes that produce ROS, and provides tolerance to plants for their better survival. AgNPs at $75 \mathrm{mg} / \mathrm{L}$, have increased the SOD and POD activities in tomato plants (Parry et al., 1994) and this has reaffirmed our present findings.

In another investigation, AgNPs at higher ratio decreased the CAT activity than control in mustard seedlings, but comparatively less reduction was observed (Vishwakarma et al., 2017). However, in the present study higher CAT activity was observed at T3 while significant reduction recorded at T5 as presented in Figure 5 which might be due to interactions of silver nanoparticles with proteins found in lipid bilayer and cytosol; thereby changing the proteins configuration resulting destruction of antioxidant defensive systems (McShan et al., 2014). Our findings are not in line with Krishnaraj et al. (2012) who have described less CAT activity in Bacopa monnieri under suitable concentrations of AgNPs. Variations in responses by different plant species have been reported by researchers whereas, the enhanced activity of CAT indicating that it plays important role to scavenge the ROS and decreases the ROS production with greater efficacy (Hayashi et al., 2013; Sneha et al., 2014).

Our findings revealed that seedlings under T3 exhibited higher TPC while lower in T5 as compared with T1 however these results are different from the previous researchers (Zaka et al., 2016) who have described increased TPC in Eruca sativa under stressed conditions along with AgNPs application. The main reason could be that high NPs ratio causes discrete changes in the proteome and interfere with cell signalling (Saptarshi et al., 2013) while on the other hand, a linear expression was observed in 
TFC. TFC were showing a significant progressive response in all treatments of AgNPs than control, reflecting improved plant growth with reduced toxic effects. In order to assess the TFC, (García-López et al., 2018) examined high TFC contents under high ZnNPs concentrations. Overall, our results are the pioneer for the evaluation of advantageous and phytotoxic effects of AgNPs in Pennisetum glaucum by stabilizing the biochemical profile and serve as guidelines for crop producer to use AgNPs instead of fungicides to get high production at low cost. Previously, the antioxidant mechanism of $P$. glaucum under AgNPs application was unknown, but recent findings will provide a particular direction to other researchers to explore genetic and molecular mechanisms for the action of AgNPs in plants.

\section{Conclusions}

This study concluded that AgNPs showed different responses to germination, seedlings growth and antioxidant activity under variable concentrations in pearl millet (P. glaucum L.). The optimum concentration of AgNPs (T3) significantly increased all the growth parameters and improved the biochemical profile as compared to other treatments. Seedlings exposed to higher doses of AgNPs showed a reduction in growth and more toxicity. Desirable secondary metabolites may be produced in plants by inducing the changes in physiological and biochemical processes with the help of nanoparticles. High doses of AgNPs seemed like a stressor and caused significant reduction in biomass. It is confirmed that higher doses of NPs are toxic to plants, even in stressed conditions (salt, drought, heat, etc.). Moreover, AgNPs at suitable concentrations can be used as a fertilizer for better crop production and fungicides to produce safe food. Shortly, this preliminary study warrants a comprehensive work to understand the toxicity of NPs at a genetic level and molecular mechanisms against undesirable molecules (free radicals) for better crop production under different environmental conditions.

Acknowledgements. Imran Khan's thanks, to Loving Parents and Brothers for their prayers and guidance, to Associate Professor Dr Muhammad Arshad for his expert advice throughout this challenging research project. This research was funded by the Modern Agro-industry Technology Research System (CARS-34) and the Sichuan Province Breeding Research grant (2016NYZ0039) and Modern Agricultural Industry System Sichuan Forage Innovation Team.

Author contributions. I.K. generated the data. All authors analysed, examined, and evaluated the data. The manuscript was written by I.K., M.A.R., S.A.A., and M.H.B.K. Statistical analysis was done by I.K. and N.I. R. New art work was completed by I.K., T.A.M. and M.N. Review was done by H.L. and N.I.R. $\mathrm{X} . Z$. helped in the final revision and editing.

Conflict of interests. The authors declare that there is no conflict of interests.

\section{REFERENCES}

[1] Abbasi, B. H., Khan, M. A., Mahmood, T., Ahmad, M., Chaudhary, M. F., Khan, M. A. (2010): Shoot regeneration and free-radical scavenging activity in Silybum marianum L. - Plant Cell, Tissue and Organ Culture (PCTOC) 101: 371-376.

[2] Aebi, H. (1984): Catalase in Vitro. - In: Slater, T. F. (ed.) Methods in Enzymology. Vol. 105. Elsevier, New York, pp. 121-126. 
[3] Alberts, B., Johnson, A., Lewis, J., Raff, M., Roberts, K., Walter, P. (2002): The shape and Structure of Proteins. - In: Alberts, B. et al. (eds.) Molecular Biology of the Cell. 4th Ed. Garland Science, New York.

[4] Austin, C. A., Hinkley, G. K. (2016): Distribution and accumulation of $10 \mathrm{~nm}$ silver nanoparticles in maternal tissues and visceral yolk sac of pregnant mice, and a potential effect on embryo growth. - Nanotoxicology 10: 654-661.

[5] Basavaraj, G., Rao, P. P., Bhagavatula, S., Ahmed, W. (2010): Availability and utilization of pearl millet in India. - SAT eJournal 8: 1-6.

[6] Bates, L. S., Waldren, R. P., Teare, I. (1973): Rapid determination of free proline for water-stress studies. - Plant and Soil 39: 205-207.

[7] Berahmand, A. A., Panahi, A. G., Sahabi, H., Feizi, H., Moghaddam, P. R., Shahtahmassebi, N., Fotovat, A., Karimpour, H., Gallehgir, O. (2012): Effects silver nanoparticles and magnetic field on growth of fodder maize (Zea mays L.). - Biological Trace Element Research 149: 419-424.

[8] Chance, B., Maehly, A. (1955): Assay of Catalases and Peroxidases. - In: Glick, D. (ed.) Methods of Biochemical Analysis. Vol. 1. Interscience Publishers, Inc., New York.

[9] Chaudhuri, S. K., Malodia, L. (2017): Biosynthesis of zinc oxide nanoparticles using leaf extract of Calotropis gigantea: characterization and its evaluation on tree seedling growth in nursery stage. - Applied Nanoscience 7: 501-512.

[10] El-Kereti, M, A., El-feky, S. A., Khater, M. S., Osman, Y. A., El-sherbini, E. S. A. (2013): $\mathrm{ZnO}$ nano fertilizer and $\mathrm{He} \mathrm{Ne}$ laser irradiation for promoting growth and yield of sweet basil plant. - Recent Patents on Food, Nutrition \& Agriculture 5: 169-181.

[11] García-López, J., Zavala-García, F., Olivares-Sáenz, E., Lira-Saldívar, R., Díaz BarrigaCastro, E., Ruiz-Torres, N., Ramos-Cortez, E., Vázquez-Alvarado, R., Niño-Medina, G. (2018): Zinc oxide nanoparticles boosts phenolic compounds and antioxidant activity of Capsicum annuum L. during germination. - Agronomy 8: 215.

[12] Gill, S. S., Tuteja, N. (2010): Reactive oxygen species and antioxidant machinery in abiotic stress tolerance in crop plants. - Plant physiology and biochemistry 48: 909-930.

[13] Hakeem, K. R. (2015): Crop Production and Global Environmental Issues. - Springer, Switzerland.

[14] Hayashi, Y., Miclaus, T., Scavenius, C., Kwiatkowska, K., Sobota, A., Engelmann, P., Scott-Fordsmand, J. J., Enghild, J. J., Sutherland, D. S. (2013): Species differences take shape at nanoparticles: protein corona made of the native repertoire assists cellular interaction. - Environmental Science \& Technology 47: 14367-14375.

[15] Hazra, G., Das, T. (2014): A review on controlled release advanced glassy fertilizer. Global J. Sci. Front. Res 14: 33-43.

[16] Hussain, M., Raja, N. I., Iqbal, M., Sabir, S., Yasmeen, F. (2017): In vitro seed germination and biochemical profiling of Artemisia absinthium exposed to various metallic nanoparticles. - 3 Biotech 7: 101.

[17] Hussain, M., Raja, N. I., Naz, F., Iqbal, M., Aslam, S. (2018): Green synthesis and characterisation of silver nanoparticles and their effects on antimicrobial efficacy and biochemical profiling in Citrus reticulata. - IET Nanobiotechnology 12: 514-519.

[18] Karimi, N., Minaei, S., Almassi, M., Shahverdi, A. (2012): Application of silver nanoparticles for protection of seeds in different soils. - African Journal of Agricultural Research 7: 1863-1869.

[19] Khan, I., Raza, M. A., Khalid, M. H. B., Awan, S. A., Raja, N. I., Zhang, X., Huang, L. (2019): Physiological and biochemical responses of pearl millet (Pennisetum glaucum L.) seedlings exposed to silver nitrate (AgNO3) and silver nanoparticles (AgNPs). International Journal of Environmental Research and Public Health 16(13): 2261.

[20] Klapheck, S., Zimmer, I., Cosse, H. (1990): Scavenging of hydrogen peroxide in the endosperm of Ricinus communis by ascorbate peroxidase. - Plant and Cell Physiology 31: 1005-1013. 
[21] Krishnaraj, C., Jagan, E., Ramachandran, R., Abirami, S., Mohan, N., Kalaichelvan, P. (2012): Effect of biologically synthesized silver nanoparticles on Bacopa monnieri (Linn.) Wettst. plant growth metabolism. - Process Biochemistry 47: 651-658.

[22] Kumari, M., Khan, S. S., Pakrashi, S., Mukherjee, A., Chandrasekaran, N. (2011): Cytogenetic and genotoxic effects of zinc oxide nanoparticles on root cells of Allium cepa. - Journal of Hazardous Materials 190: 613-621.

[23] Lee, W. M., An, Y. J., Yoon, H., Kweon, H. S. (2008): Toxicity and bioavailability of copper nanoparticles to the terrestrial plants mung bean (Phaseolus radiatus) and wheat (Triticum aestivum): plant agar test for water-insoluble nanoparticles. - Environmental Toxicology and Chemistry 27: 1915-1921.

[24] Lopez-Contreras, J. J., Zavala-Garcia, F., Urias-Orona, V., Martinez-Avila, G. C. G., Rojas, R., Guillermo, N. M. (2015): Chromatic, phenolic and antioxidant properties of Sorghum bicolor genotypes. - Notulae Botanicae Horti Agrobotanici Cluj-Napoca 43: 366-370.

[25] Majdalawieh, A., Kanan, M. C., El-Kadri, O., Kanan, S. M. (2014): Recent advances in gold and silver nanoparticles: synthesis and applications. - Journal of Nanoscience and Nanotechnology 14: 4757-4780.

[26] McShan, D., Ray, P. C., Yu, H. (2014): Molecular toxicity mechanism of nanosilver. Journal of Food and Drug Analysis 22: 116-127.

[27] Mirzajani, F., Askari, H., Hamzelou, S., Farzaneh, M., Ghassempour, A. (2013) Effect of silver nanoparticles on Oryza sativa L. and its rhizosphere bacteria. - Ecotoxicology and Environmental Safety 88: 48-54.

[28] Mittal, R., Mittal, C. G. (2013): Impact of population explosion on environment. - The Nat. J. 1: 1-5.

[29] Mohamed, A. K. S., Qayyum, M. F., Abdel-Hadi, A. M., Rehman, R. A., Ali, S., Rizwan, M. (2017) Interactive effect of salinity and silver nanoparticles on photosynthetic and biochemical parameters of wheat. - Archives of Agronomy and Soil Science 63: 17361747.

[30] Okarter, N., Liu, R. H. (2010): Health benefits of whole grain phytochemicals. - Critical Reviews in Food Science and Nutrition 50: 193-208.

[31] Parry, A. D., Tiller, S. A., Edwards, R. (1994): The effects of heavy metals and root immersion on isoflavonoid metabolism in alfalfa (Medicago sativa L.). - Plant Physiology 106: 195-202.

[32] Parveen, A., Rao, S. (2015): Effect of nanosilver on seed germination and seedling growth in Pennisetum glaucum. - Journal of Cluster Science 26: 693-701.

[33] Patra, S., Mishra, P., Mahapatra, S., Mithun, S. (2016): Modelling impacts of chemical fertilizer on agricultural production: a case study on Hooghly district, West Bengal, India. - Modeling Earth Systems and Environment 2: 1-11.

[34] Rafi, Z. N., Ramezanian, A. (2013): Vase life of cut rose cultivars 'Avalanche' and 'Fiesta' as affected by Nano-Silver and S-carvone treatments. - South African Journal of Botany 86: 68-72.

[35] Saptarshi, S. R., Duschl, A., Lopata, A. L. (2013): Interaction of nanoparticles with proteins: relation to bio-reactivity of the nanoparticle. - Journal of Nanobiotechnology 11: 26.

[36] Sewelam, N., Kazan, K., Schenk, P. M. (2016): Global plant stress signaling: reactive oxygen species at the cross-road. - Frontiers in Plant Science 7: 187.

[37] Sneha, S., Rishi, A., Chandra, S. (2014): Effect of short term salt stress on chlorophyll content, protein and activities of catalase and ascorbate peroxidase enzymes in pearl millet. - Am. J. Plant Physiol 9: 32-37.

[38] Szabados, L., Savoure, A. (2010): Proline: a multifunctional amino acid. - Trends in Plant Science 15: 89-97.

[39] Thakkar, K. N., Mhatre, S. S., Parikh, R. Y. (2010): Biological synthesis of metallic nanoparticles. - Nanomedicine: Nanotechnology, Biology and Medicine 6: 257-262. 
[40] Tripathi, D. K., Mishra, R. K. (2017) Nitric oxide ameliorates zinc oxide nanoparticles phytotoxicity in wheat seedlings: implication of the ascorbate-glutathione cycle. Frontiers in Plant Science 8: 1.

[41] Ullah, N., Haq, I. U., Safdar, N., Mirza, B. (2015): Physiological and biochemical mechanisms of allelopathy mediated by the allelochemical extracts of Phytolacca latbenia (Moq.) H. Walter. - Toxicology and Industrial Health 31: 931-937.

[42] Ushahra, J., Malik, C. (2013): Putrescine and ascorbic acid mediated enhancement in growth and antioxidant status of Eruca sativa varieties. - CIB Tech J Biotechnol 2: 53-64.

[43] van Dongen, J. T., Ammerlaan, A. M., Wouterlood, M., van Aelst, A. C., Borstlap, A. C. (2003): Structure of the developing pea seed coat and the post-phloem transport pathway of nutrients. - Annals of Botany 91: 729-737.

[44] Vejan, P., Abdullah, R., Khadiran, T., Ismail, S., Nasrulhaq, Boyce, A. (2016): Role of plant growth promoting rhizobacteria in agricultural sustainability-a review. Molecules 21: 573.

[45] Velioglu, Y., Mazza, G., Gao, L., Oomah, B. (1998): Antioxidant activity and total phenolics in selected fruits, vegetables, and grain products. - Journal of Agricultural and Food Chemistry 46: 4113-4117.

[46] Vishwakarma, K., Upadhyay, N. (2017) Abscisic acid signaling and abiotic stress tolerance in plants: a review on current knowledge and future prospects. - Frontiers in Plant Science 8: 161.

[47] Wang, C., Yan, H., Li, J., Zhou, S., Liu, T., Zhang, X., Huang, L. (2018): Genome survey sequencing of purple elephant grass (Pennisetum purpureum Schum 'Zise') and identification of its SSR markers. - Molecular Breeding 38(7): 94.

[48] Yang, S. L., Lan, S. S., Gong, M. (2009): Hydrogen peroxide-induced proline and metabolic pathway of its accumulation in maize seedlings. - Journal of Plant Physiology 166: 1694-1699.

[49] Yasur, J., Rani, P. U. (2013): Environmental effects of nanosilver: impact on castor seed germination, seedling growth, and plant physiology. - Environmental Science and Pollution Research 20: 8636-8648.

[50] Zaka, M., Abbasi, B. H., Rahman, L. U., Shah, A., Zia, M. (2016): Synthesis and characterisation of metal nanoparticles and their effects on seed germination and seedling growth in commercially important Eruca sativa. - IET Nanobiotechnology 10: 134-140.

[51] Zhou, S., Wang, C., Frazier, T. P., Yan, H., Chen, P., Chen, Z., Yan, Y. (2018): The first Illumina-based de novo transcriptome analysis and molecular marker development in Napier grass (Pennisetum purpureum). - Molecular Breeding 38(7): 95.

[52] Zhou, S., Chen, J., Lai, Y., Yin, G., Chen, P., Pennerman, K. K., Wang, C. (2019a): Integrative analysis of metabolome and transcriptome reveals anthocyanins biosynthesis regulation in grass species Pennisetum purpureum. - Industrial Crops and Products 138: 111470.

[53] Zhou, S., Wang, C., Yin, G., Zhang, Y., Shen, X., Pennerman, K. K., Ren, S. (2019b): Phylogenetics and diversity analysis of Pennisetum species using Hemarthria EST-SSR markers. - Grassland Science 65(1): 13-22.

[54] Zou, X., Li, P., Huang, Q., Zhang, H. (2016): The different response mechanisms of Wolffia globosa: light-induced silver nanoparticle toxicity. - Aquatic Toxicology 176: 97-105. 